\title{
Adaptive control systems for solar collectors
}

\author{
Omar Flor Unda \\ ORCID: https://orcid.org/0000-0001-5302-141X \\ Omar.flor@udla.edu.ec \\ Universidad de las Americas, School of Engineering \\ and Applied Sciences, Industrial Engineering Career \\ Quito-Ecuador
}

Received (06/04/21), Accepted (10/05/21)

\begin{abstract}
En este trabajo se presentan las estrategias de control del flujo de aceite mediante la técnica de Control Predictivo basado en Modelo, para el mecanismo de control del campo de colectores solares cilindros parabólicos. Se analiza el comportamiento dinámico del sistema con el uso del modelo matemático, una técnica de control self-tunning y controlador predictivo basado en modelo para el control de plantas tipo ACUREX.
\end{abstract}

Keywords: Automation, Modernization, ControlLogix, Supervisory System, Mimic Panel

\section{Sistemas de control adaptativo para colectores solares}

Resumen: En este trabajo se presentan las estrategias de control del flujo de aceite mediante la técnica de Control Predictivo basado en Modelo, para el mecanismo de control del campo de colectores solares cilindros parabólicos. Se analiza el comportamiento dinámico del sistema con el uso del modelo matemático, una técnica de control self-tunning y controlador predictivo basado en modelo para el control de plantas tipo ACUREX.

Palabras Clave: Autómata, Modernización, ControlLogix, Sistema Supervisorio, Panel Mímico. 


\section{I.INTRODUCTION}

The use of clean energy on the planet is increasingly necessary, research in this area is becoming more frequent and important to better preserve our environment and natural resources.

There are currently a growing number of solar plants generating electricity or heat energy that can be used for human consumption or industrial processes. One of the experimental solar plants in Spain is the one in Almeria. Some control strategies have been tested in the last 30 years, seeking better performance and control of the temperature of the oil that this system uses in its operation, the energy of solar radiation is absorbed and transported by a thermal fluid for later use.

It is of interest new alternatives and criteria that allow the continuous improvement of this type of plant. This work intends to contribute with criteria on the use of the Model-Based Predictive Control technique that can serve as a basis with criteria for further developments.

\section{DEVELOPMENT}

\section{A. Simulator in Simulink of the ACUREX type Collector Field}

\section{Process Model}

Considering the basic operation of the collector field and the more detailed description of Arahal [1], the following is a brief explanation of the development of the model, as well as the variables necessary for the control employing the simulator.

Taking into account the principle of conservation of energy to the metal pipe and considering the thermal phenomenon of the oil-absorbing energy, a mathematical model has been developed [1] with which the initial estimation of the temperature of the fluid (f) and the metal (m) of the pipe is allowed.

$$
\begin{aligned}
& \rho_{m} c_{m} A_{m} \frac{\partial T_{m}}{\partial t}=I \eta_{o} D-H_{1} G\left(T_{m}-T_{a}\right)-L H_{t}\left(T_{m}-T_{f}\right) \\
& \rho_{f} C_{f} A_{f} \frac{\partial T_{f}}{\partial t}+\rho_{f} C_{f} \dot{V} \frac{\partial T_{f}}{\partial x}=L H_{t}\left(T_{m}-T_{f}\right)
\end{aligned}
$$

Table 1. Variables used in equations (1) and (2)

\begin{tabular}{|c|c|c|}
\hline Symbol & Description & Units \\
\hline$t$ & Time & $\mathrm{m}$ \\
\hline$x$ & Length & $\mathrm{kgm}^{-3}$ \\
\hline$\rho$ & Oil Density & $\mathrm{JK}^{-1} \mathrm{~kg}^{-1}$ \\
\hline$c$ & Specific Heat & $\mathrm{m}^{2}$ \\
\hline$T$ & Cross-sectional area & $\mathrm{K}^{\circ} \mathrm{C}$ \\
\hline$T$ & Outlet temperature & $W \mathrm{~m}^{-2}$ \\
\hline$H_{1}$ & $\begin{array}{l}\text { Global coefficient of thermal } \\
\text { loss }\end{array}$ & $W \mathrm{~m}^{-2} \mathrm{C}^{-1}$ \\
\hline
\end{tabular}




\begin{tabular}{|c|c|c|}
\hline$D$ & Reflective surface width & $m$ \\
\hline$H_{t}$ & $\begin{array}{c}\text { Metal-fluid heat transfer } \\
\text { coefficient }\end{array}$ & $\mathrm{W} \mathrm{m}^{-2} \mathrm{C}^{-1}$ \\
\hline$G$ & Manifold opening & $m$ \\
\hline$L$ & Linear tube length & $m$ \\
\hline$\dot{V}$ & Oil flow & $\mathrm{m}^{2} \mathrm{~s}^{-1}$ \\
\hline$\eta_{0}$ & Geometric efficiency & - \\
\hline$T_{a}$ & Room temperature & $K,{ }^{\circ} \mathrm{C}$ \\
\hline
\end{tabular}

As the system is composed of several collectors connected in series, some of them may be inactive for maintenance reasons, therefore equations (1) and (2) will be taken into account for the control only for the active areas of the field, considering the number of active and non-active collectors. Table 2 details the parameters used in the mathematical model.

\section{Process Simulator in Simulink-Matlab}

The Simulink simulator was originally developed in C language and then adapted with the use of MEX files.

Two stages are considered for the simulation. The first one calculates the fluid and metal temperature considering (1) and (2), a stationary regime is assumed. The second stage considers the energy transported in the fluid.

Two models are used for this simulation. The distributed model of the collector field was obtained by using the energy conservation principle. In addition, parameter adjustment models are used, which have been achieved through the adjustment of polynomial functions as a function of temperature by the method of least squares.

To simulate the system, data feedback is used, taking into account the handling of 39 variables that are updated as the process is simulated. Real data measured on September 16, 1991, are also considered. The simulation day is considered from 8:50 a.m. and its duration time is 6 hours and 36 minutes, the sampling time is 39 seconds [2].

\section{B.Adaptive Control}

This type of control ensures that the automatic control system adapts to varying circumstances of behavior in the dynamics of a system and its disturbances.

A useful definition would be that Adaptive Control is a special type of nonlinear control in which the process state can be separated into two-time scales that evolve at different speeds. The slow scale corresponds to the parameter changes and therefore to the speed with which the controller parameters are modified, and the fast scale corresponds to the dynamics of the ordinary feedback loop [3].

We appreciate in Figure $1 \mathrm{a}$ basic scheme of adaptive control. There is a negative feedback loop, a controller acts, and another loop where the performance is evaluated, the error is compared with the desired performance, and with the help of an adaptive mechanism, the controller parameters are adjusted, and sometimes it acts directly on the control signal. There may also be a third loop with the task of monitoring the performance of the previous two loops. 


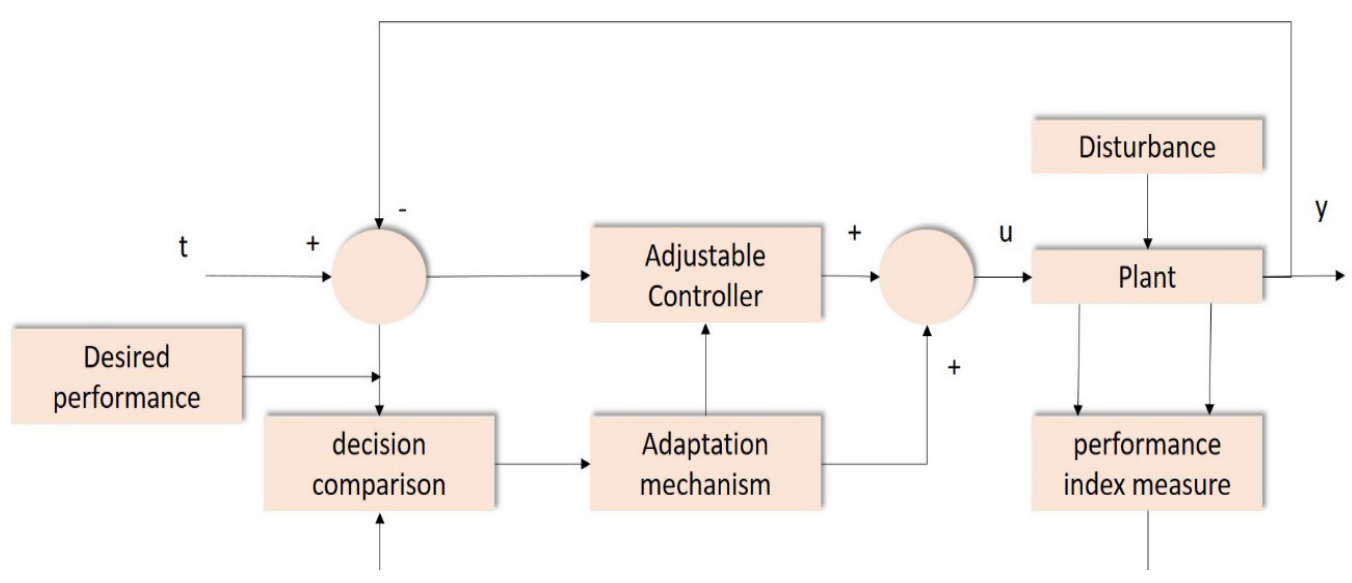

Fig 1. Basic configuration of a adaptive control.

\section{III.METHODOLOGY}

In this work and to find alternative solutions, the predictive controller has been implemented in three situations that could be useful or as a basis for future developments.

The mathematical combination of the Prefeed Block and Plant has been carried out, and the predictive controller has been designed with this model.

The second case is the simulation of the system with MPC and the use of an identifier to estimate a fixed model of the Prefeed and Plant blocks and use it in the control.

The third case corresponds to the previous identifier placed online in the simulation that will allow estimating the parameters of the model as it evolves and thus adjusts the controller, this being a case of adaptive control to some degree.

Considering the mathematical model, the predictive controller has been implemented in the simulator. Figure 2 shows the scheme used in Simulink for the control. The replacement of the PI controller block is observed. Some functions have been created in Matlab and used to adapt them to the simulator functions.

The blocks are fed externally to individualize the main parameters such as IRR, T_in, T_AMB, T_REF. The function that obtains the corrected radiation is placed immediately to the Irradiation to feed the blocks, this function used to belong to the pre-fed block.

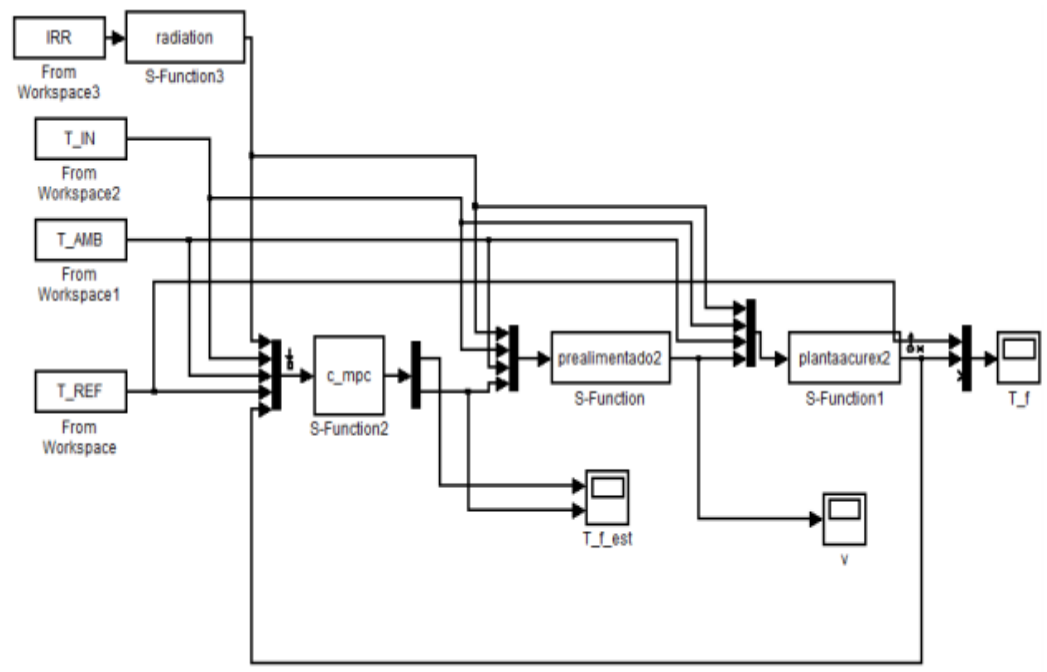

Figure 2. MPC simulator (mathematical model and fixed estimate) 


\section{IV.RESULTS}

\section{A.MPC with Mathematics Model}

The data used in the simulations are obtained from the simulator file SA910916.1st, which provides the values of Irradiance and Corrected Radiation, these parameters are presented in Figure 3, it is observed that the corrected radiation manages to improve the irregular behavior of the direct radiation. Although it is not fully exploited, at least it contributes to a more stable value for the simulation.

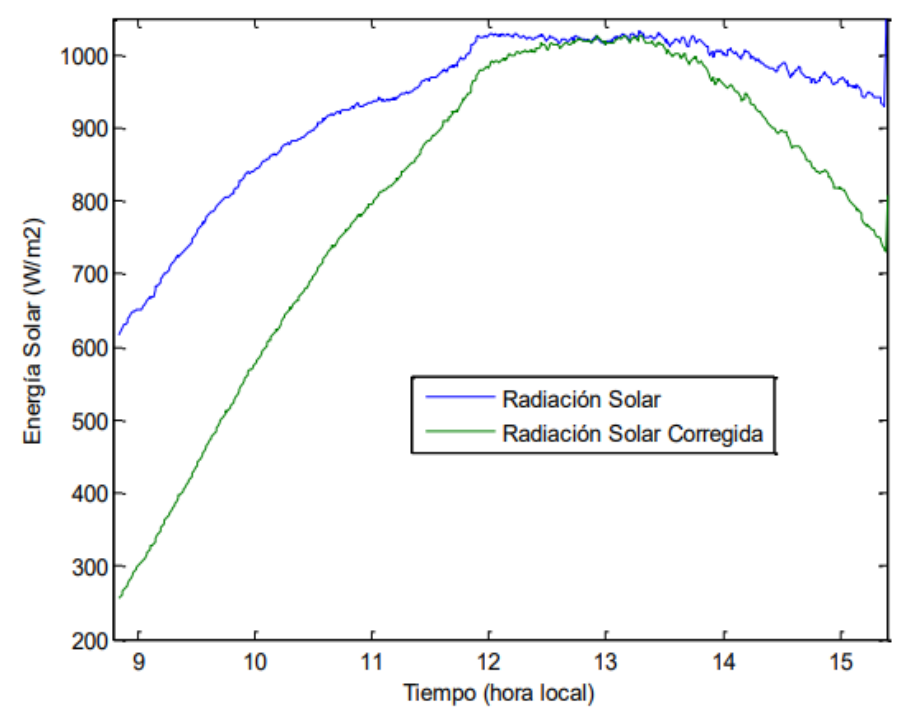

\section{Fig 3. Solar Radiation and Corrected Radiation}

Figure 4 shows the system reference, the inlet temperature, and the outlet temperature of the oil. The green line shows an irregular behavior of the temperature, which is provided by the controller using the mathematical model. The output in the red line although it adequately follows the reference, presents an oscillatory behavior throughout the time in a $+-4{ }^{\circ} \mathrm{C}$ band. It is observed that the settling time is acceptable, taking approximately 12 minutes to reach the aforementioned band.

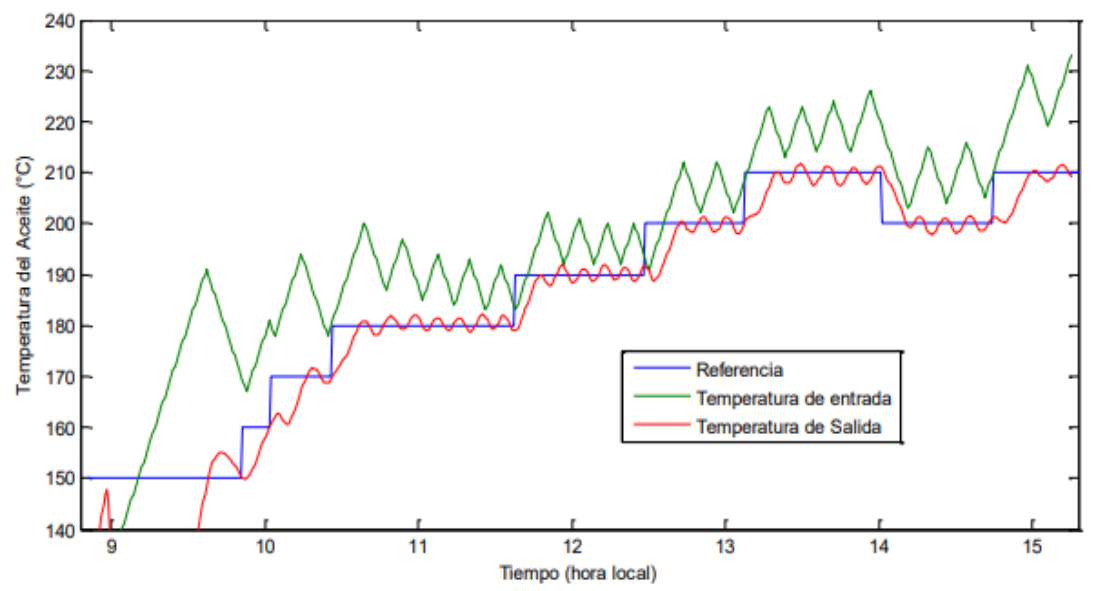

Fig 4. System inlet and outlet temperature (mathematical model)

\section{B.MPC With Estimated Fixed Model}

Figure 5 shows the system reference, the inlet temperature, and the outlet temperature of the oil when the fixed estimated model was used with the MPC controller. The green line shows an irregular behavior, lower than the 
previous case. The output in the red line adequately follows the reference until it exceeds $190^{\circ}$ where the behavior generates an offset that increases and deteriorates the output behavior. It is observed that the oscillatory behavior has been reduced. This generated offset would need some integral action to improve its performance in case this method is used in future controls.

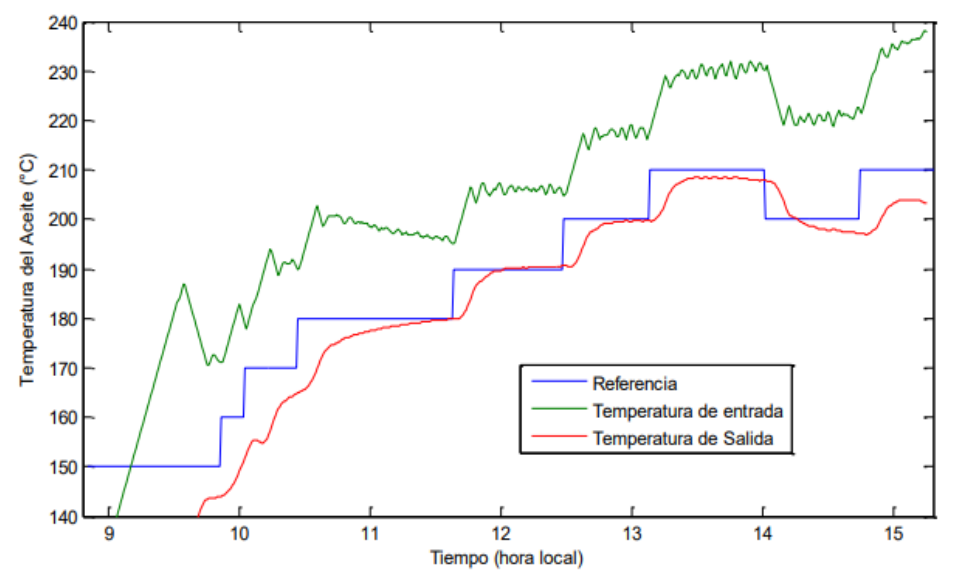

Fig 5. System inlet and outlet temperature (MPC fixed model)

\section{V.CONCLUSIONS}

-As it has been observed the use of predictive control is a technique that adapts to a variety of models allowing the solution of a large number of control problems. In this case, it did so although the power source is not adjustable and intermittent, still managed to solve such systems. Hence the growth of its expectation in the industrial field.

- The use of the simulator allows to conclude in a better way the applied techniques and compare them based on the fact that the radiation conditions for the plant are not reproducible from one day to the other, the simulator allows through its design to implement new control techniques being a very useful academic.

- As observed, the change in the operating point generates variation in the model, the simulator data does not allow comparison with other operations at different operating points, it would be useful to have more data on changes in the reference point to conclude how the system varies and the true reason for the offset generated in the responses.

\section{REFERENCES}

[1]Arahal, M. R., Berenguel, M. \& Camacho, E. F., 1997. Nonlinear neural model-based predictive control of a solar plant. In Proc. European Control Conf. ECC'97. Brussels, Belgium, Volumen TH-E I2, p. paper 264.

[2]Arahal, M. R., Berenguel, M. \& Camacho, E. F., 1998a. Comparison of RBF algorithms for output temperature prediction of a solar plant.. In Proc. CONTROLO'98, 9-11 September.

[3]Arahal, M. R., Berenguel, M. \& Camacho, E. F., 1998b. Neural identification applied to predictive control of solar plant. Control Engineering Practice, Volumen 6, pp. pp. 333-344.

[4]Aström, K. J. \& Wittenmark, B., 1989. Adaptative Control. Aström, K. J. \& Wittermark, B., 1984. Computed controlles Systems, Theory and Design. Englewood Cliffs, NJ: Prentice Hall.

[5]Barão, M., 2000. Dynamic and no-linear control of a solar collector field. Thesis (in Portuguese). Universidade Técnica de Lisboa, Instituto Superior Técnico.

[6]Barão, M., Lemos, J. M. \& Silva, R. N., 2002. Reduced complexity adaptative nonlinear control of a distribuited collector solar field. J. of Process Control, Volumen 12(1), pp. pp. 131-141.

[7]Berenguel, M., Arahal, M. R. \& Camacho, E. F., 1998. Modeling free responses of a solar plant for predictive control. Control Engineering Practice, Volumen 6, pp. pp. 1257-1266.

[8]Berenguel, M., Camacho, E. F. \& Rubio, F. R., 1994. Simulation software package for the Acurex field.. Departamento de Ingeniería y Automática.

[9]Berenguel, M., Camacho, E. F. \& Rubio, F. R., 1997. Advanced Control of Solar Plants. Londres: Springer-Verlag. 


\section{CURRICULUM SUMMARY}

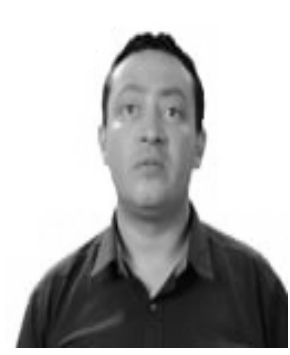

Omar Flor, Mechanical Engineer from the Army Polytechnic School, Master in Automation, Robotics and Telematics at the University of Seville-Spain, professor and researcher at the University of the Americas in Quito-Ecuador. 